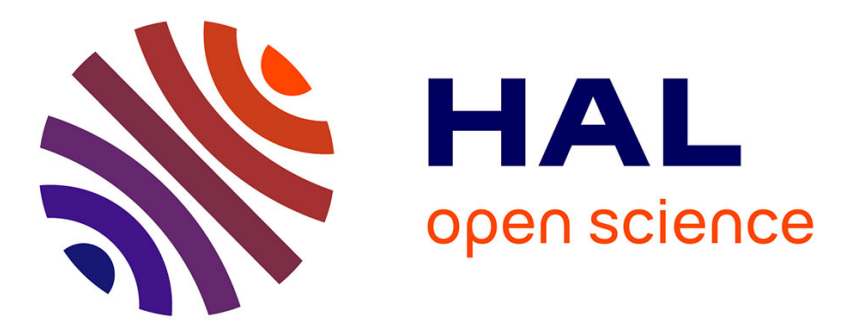

\title{
Providing Life-Style-Intervention to Improve Well-Being of Elderly People
}

Thomas Rist, Andreas Seiderer, Elisabeth André

\section{To cite this version:}

Thomas Rist, Andreas Seiderer, Elisabeth André. Providing Life-Style-Intervention to Improve WellBeing of Elderly People. 17th International Conference on Entertainment Computing (ICEC), Sep 2018, Poznan, Poland. pp.362-367, 10.1007/978-3-319-99426-0_45 . hal-02128600

\section{HAL Id: hal-02128600 \\ https://hal.inria.fr/hal-02128600}

Submitted on 14 May 2019

HAL is a multi-disciplinary open access archive for the deposit and dissemination of scientific research documents, whether they are published or not. The documents may come from teaching and research institutions in France or abroad, or from public or private research centers.
L'archive ouverte pluridisciplinaire HAL, est destinée au dépôt et à la diffusion de documents scientifiques de niveau recherche, publiés ou non, émanant des établissements d'enseignement et de recherche français ou étrangers, des laboratoires publics ou privés. 


\title{
Providing Life-style-Intervention to Improve Well-Being of Elderly People
}

\author{
Thomas Rist ${ }^{1}$, Andreas Seiderer ${ }^{2}$ and Elisabeth André ${ }^{2}$ \\ ${ }^{1}$ Hochschule Augsburg, Germany \\ ${ }^{2}$ Universität Augsburg, Germany \\ Thomas.Ristehs-augsburg.de
}

\begin{abstract}
We report on a user-centered approach towards the development of an augmented digital picture frame - called "CARE" - for senior users with the aim to improve their general well-being. The central idea is to interleave the display of pictures with the provision of recommendations of activities that seniors may perform in addition to their ordinary daily routines. We also report on our attempt to encourage durable use of the CARE system by introducing reward schemes for recommended activities. Feedback from users suggests that reward schemes should be made individually configurable.
\end{abstract}

Keywords: Ambient Assisted Living, Gamification, Senior-centered Design

\section{Introduction}

Aging - sooner or later - goes hand in hand with a decline in physical performance and intellectual functions. Many elderly people suffer from various kinds of diseases, some of which can be chronic. Physical impairments definitely have an impact on their everyday life and also their psychological state. Therefore, lifestyle choices are among the most important factors that determine a person's well-being and quality of life. Studies have shown that regular physical activities can help mitigate many agerelated diseases. Furthermore, creative activities, such as painting, have a positive influence on well-being. Studies conducted in a senior citizen's apartment building have shown that interventions that encourage the elderly to participate in activities, such as taking over responsibility for household chores, have been effective means to prevent social isolation and loneliness.

We report on the CARE project (a sentient Context-Aware Recommender system for the Elderly) which makes use of a digital picture frame as display device for providing recommendations [1]. Recommendations are chosen on the basis of data acquired by sensors embedded in the user's environment and possibly body-worn sensors as well as a user model, a discourse model, and a model of well-being factors to carefully decide on at which point in time what kind of activity will be most suitable to suggest in order to increase the user's well-being.

Whether a system like CARE can reach its aims essentially depends on whether the given recommendations are actually followed in general and - depending on the kind of recommendation - how accurately they are followed. Also as CARE has been de- 
signed for long term usage, users need to be encouraged to follow repeatedly recommended activities. With the ambition to increase the effectiveness of CARE, it was questioned, in what way well-known computer game elements and principles, such as live feedback and especially rewards, may be used to enhance the user's overall appreciation of the CARE system. To find out which activities recommended by CARE should get rewarded and what kind of rewards would be appropriate, we prepared and ran a co-design workshop with a peer group of senior citizens.

\section{Requirements Gathering}

To inform the design of the envisioned system, we recruited a peer group of potential users, 27 German seniors (aged 59-92, 12 male, 15 female), and conducted structured interviews which were focused on the seniors' life-style, medical needs, attitude towards so-called Ambient Assisted Living technologies, and, more specifically, on desired functions of a CARE system (reminders, recommendations etc.) and preferences for a certain configuration (display type, presentation media and interaction modalities) system configurations of a system that gives them recommendations.

The most frequently desired functions were: (a) services that would remind them of intaking medicine, regular drinking and important dates, (b) sending emergency calls to family members and medical staff in case of accidents and illness, (c) warnings concerning not-switched-off electrical appliances, lights or open windows when leaving the house or going to bed. In addition, seniors saw a benefit in getting recommendations for healthy nutrition, physical activity and mental training. Regarding system configuration there was no clear winner among the presented interaction devices (tablet, picture frame, smartphone, smartwatch, humanoid robot) although the smartwatch was slightly preferred over the other devices. Regarding interaction modalities, some of the interviewees mentioned speech-based interaction as desirable, in particular for the smartwatches due to their small displays and for the robots.

\section{CARE Prototypes}

After requirement gathering we decided to deploy a digital picture frame as display device for providing recommendations. However, CARE makes a substantial extension to the classical concept of a digital picture frame. It interleaves the display of photos with physical exercises, brain-twisters and situation-specific life style recommendations, i.e. it switches between a picture frame mode and a recommender mode.
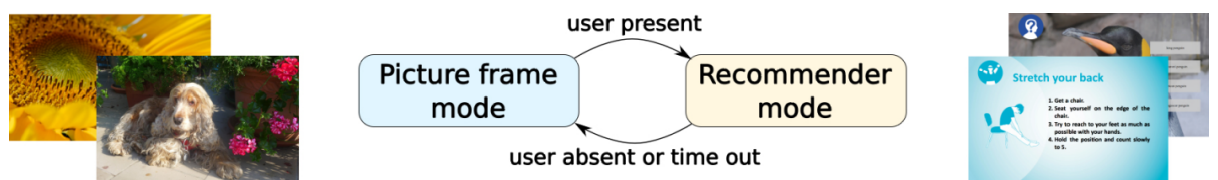

Fig. 1: Digital picture frame augmented by a recommender mode 
In Picture frame mode, CARE appears to the user like an ordinary picture frame that displays photos that are either taken from local repository, or which are remotely uploaded by family members via an internet connection (Fig. 1 left). The Picture frame mode is usually active when the user is further away from the display.

In recommender mode users receive context-specific recommendations (Fig 1 right) chosen on the basis of: (a) data acquired by sensors embedded in the user's environment and possibly body-worn sensors, (b) a user model, (c) a discourse model, and (d) a model of well-being factors to carefully decide on at which point in time what kind of activity will be most suitable to suggest in order to increase the user's well-being.

For the sake of simplicity, CARE switches to recommender mode every time a user is detected in front of the display for a minimum of two seconds.

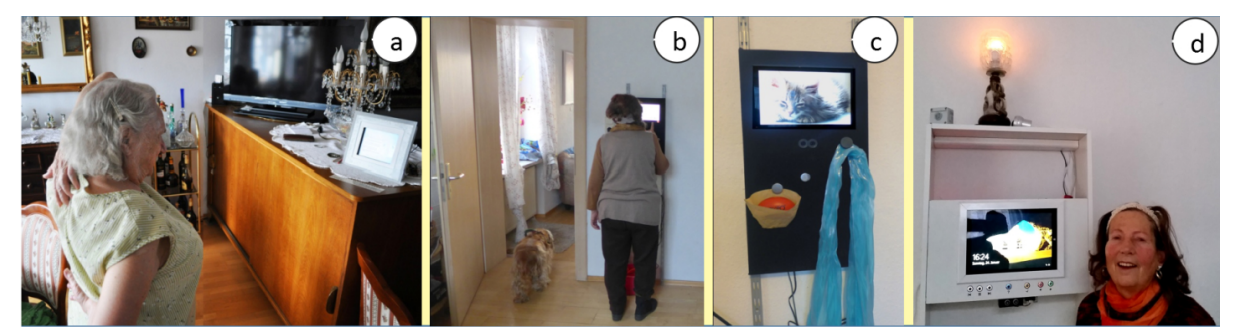

Fig. 2: Different versions of CARE prototypes

During the project, several versions of CARE prototypes have been developed and tested in living environments of pilot users. A first proof-of-concept version was based on a tablet PC cased in a wooden frame so that it appeared as an ordinary digital picture frame (Fig. 2a). It turned out that the readability of presented recommendations would benefit if the display screen was mounted at the user's eye level. This leads to a CARE version that was mounted on a rack rail (Fig 2b). In addition, this version featured a magnetic pin board which allowed users to stick notes on it, and also to store some items such as a stretch band, needed for certain physical exercises. (Fig. 2c). A revised version of CARE has been integrated in a shelf (Fig 2d). This version features both soft buttons as well as external hardware buttons to ease interaction in case a person feels more comfortable pressing hardware buttons than soft-buttons on the screen. In addition, this version can be connected with an ambient light to indicate that the user may have a look at CARE as there are new recommendations.

\section{Rewarding Schemes for Recommended Activities}

With the ambition to increase the effectiveness of CARE, it was questioned, in what way well-known computer game elements and principles, such as live feedback and especially rewards, may be used to enhance the user's overall appreciation of the CARE system. The idea is to link given recommendations with some measurable indicators of whether or not recommendations have been followed. For instance, if the 
recommender system suggests a physical exercise, a possible indicator is the number of repetitions or just elapsed exercising time.

Initially, we speculated that a uniform rewarding scheme across all kinds of recommended activities would increase the users' perception of CARE as a coherent recommendation system. Following this approach, measured indicators for different recommendations are mapped onto abstract points, which in turn are mapped to a rewarding scheme of choice, such as score boards, badges or virtual currencies. Scores encompass rewarding in form of comparison with oneself, like a high-score in speed races, and with other players in a leaderboard. Badges are a means to represent the status of each player (CARE user) by providing him or her with awards or the recognition by others. The virtual currency category stands for all kind of rewards which can be exchanged with virtual or real goods. For instance, virtual coins may be used to purchase yet needed pieces of a jigsaw puzzle on screen or to have a virtual plant grow and prosper. Another option would be to use the coins for purchasing real-world goods, such as a cup of coffee.

However, there was uncertainty which recommended activities should get rewarded at all, and what kind of rewards users would find appropriate. To shed light on these questions we arranged two user workshops (W1, W2) with elderly people, having in mind the following objectives (1) to learn about the daily routines of the participants and their engagement in activities that promote a healthy lifestyle, (2) to elicit feedback on technology that actively gives recommendations and suggests activities, and (3) to gather opinions on meaningful rewarding schemes for recommended activities and (4) to learn about contextual factors, such different living environments.

For workshop W1 we established contact with a local seniors' association and recruited a group of seniors (aged 60-70, 11 female, 1 male). All seniors are retired, live independently, and maintain their own households. In contrast, for the second workshop (W2) we recruited nine residents (aged 80+, 8 female, 1 male). Compared to $\mathrm{W} 1$ participants, members of this age group were notably suffering more strongly from age-related impairments, such as limited mobility and lower levels of cognitive performance.

To elicit information about the participants' daily routines and activities, and to reveal their attitudes towards rewarding schemes, a working sheet with a timeline and three piles of cards have been prepared. The first pile consisted of cards depicting daily routines. Cards of the second pile showed activities that CARE would recommend for promoting a healthier lifestyle, e.g. physical or mental exercises. By means of cards from the third pile, participants could allocate different kinds of reward to activities. While there is a huge variety of possible rewards, we focused on three types of reward, which we found suitable for CARE: scores, badges and virtual currencies. Finally, several blank cards were included so that participants could use them to write down additional activities or rewards for which no cards had been prepared. With exception of blank cards, the visual appearance of all cards resembled the graphical style used for screen content displayed by the CARE system.

Workshop W1 took place at a senior meeting center, while W2 was held in an assembly room of the retirement home. Both workshops were administered by one female and two male experimenters. In the workshops, participants: 
- received an introduction to CARE including the opportunity to practice instructed and monitored by the system,

- got an explanation of their role in helping us extend and improve CARE,

- took part in three card-laying tasks to inform us about daily routines and activities, and to reveal their attitudes towards rewarding schemes,

- were asked to provide verbal feedback on a number of predefined questions which are to be prompted by the experimenters during the workshop

Throughout the workshops three experimenters took notes on verbal responses and comments, and took pictures of the outcomes of the card-laying tasks. Grouping and analysis of the recorded material took place after each workshop.

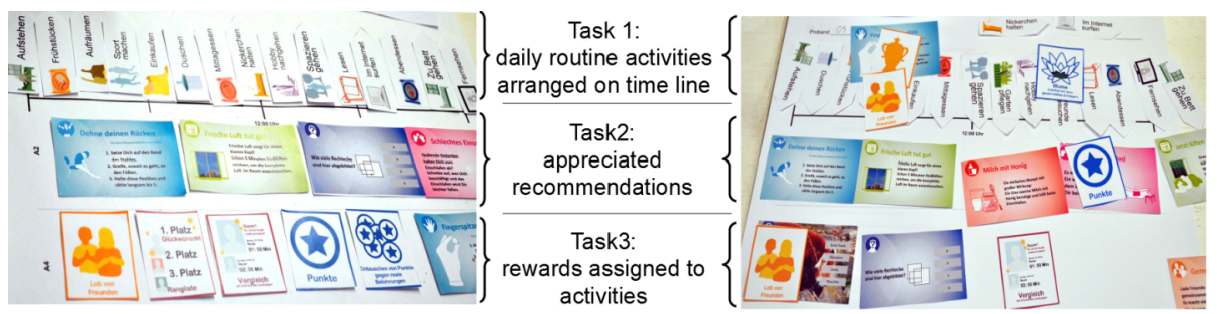

Fig. 3. Two samples of finished worksheets.

Participants first laid out their typical daily schedule (Task 1), then indicated preferences for potential recommendations (Task 2), and indicated for which of the recommended activities they would appreciate receiving rewards (Task 3).

Examining W1 and W2 worksheets to see which activities got associated with rewards (scores, badges, or virtual currency) revealed a quite heterogeneous picture. Only 4 out of 9 W2 participants wanted to receive rewards at all. In contrast, W1 participants were more open towards the idea of receiving rewards. Only one W1 participant did not assign any reward arguing that having accomplished an activity is enough rewarding itself and doesn't need an extra reward on top of it. Three W1 participants rewarded only activities which were already part of their agendas (such as cleaning, gardening, or surfing the Internet as this was considered a challenging activity), but not to recommended activities. In contrast, $7 \mathrm{~W} 1$ participants only rewarded recommended activities; and only one participant rewarded both routine activities as well as recommended activities.

With regard to reward types we observed among W1 participants a strong preference (21 cases) for virtual currencies that could be used to purchase real or virtual goods. Several suggestions were given for potential exchanges, such as using collected virtual currency for sports equipment. Badges were assigned in 6 cases, and scores in another 5 cases. Only $3 \mathrm{~W} 1$ participants rewarded activities consistently with the same type of reward, while all others suggested different reward types for different activities. We did not observe dominant occurrences of activity/reward associations among all $\mathrm{W} 1$ and $\mathrm{W} 2$ participants, but a variety of individual preferences. There was common agreement among the participants of both workshops that it is often the activity itself or its outcome that constitutes a tangible reward to them. 


\section{$5 \quad$ Related Work}

The concept of a digital picture frame has also been researched by Rowan and Mynatt [2] to enhance awareness within a family of a senior's daily life by augmenting a portrait of the elderly person with data related to health and well-being. Lumsden et al. [3] reviewed 33 studies of gamified applications for cognitive training and identified a number of different reasons for deploying game elements in cognitive training and testing, including the aim to increase the users' motivation and long-term engagement, as well as usability, intuitiveness and appeal of an application. Johnson et al. [4] revisited 19 papers that report empirical evidence on the effect of gamified physical as well as mental exercises on health and wellbeing. While the majority of studies suggest that gamification has worked in many cases, it still remains a challenge for application designers to decide on which gamifying elements should be added because they are likely to add value to an application, and which ones should be neglected since they may even cause opposite effects. Suggestions for application design can be extracted from works compiling gamification guidelines based on interviews with seniors [5].

\section{Conclusions}

In this paper, we described work towards a recommender system for elderly people with the ultimate objective to contribute positively to a senior person's well-being through little interventions provided during the day in the form of contextualized recommendations which are related to factors that determine well-being. After first user studies, we feel encouraged to incorporate a reward mechanism into CARE. However, we no longer think that a uniform rewarding scheme across all recommendation types is the approach of choice. Therefore, we will give users the opportunity to configure the rewarding schemes individually.

\section{References}

1. Rist, T., Seiderer, A., Hammer, S., Mayr, M., and André, E.: CARE: Extending a Digital Picture Frame with a Recommender Mode to Enhance Well-being of Elderly People. In Pervasive Health 2015.112-120. (2015).

2. Rowan, J and Mynatt, E. D.: "Digital family portrait field trial: Supportfor aging in place," in Proc. of CHI '05. New York, NY, USA: ACM, 2005, pp. 521-530. (2005).

3. Lumsden, J., Edwards, E. A., Lawrence, N. S., Coyle, D. and Munò, M. R.: Gamification of cognitive assessment and cognitive training: a systematic review of applications and efficacy. JMIR Serious Games 4, 2(2016).

4. Johnson, D., Deterding, S., Kuhn, K.-A., Staneva, A., Stoyanov, S. and Hides, L.: Gamification for health and wellbeing: A systematic review of the literature. Internet Interventions 6, 89-106 (2016).

5. De Schutter B. and VanDen Abeele, V.: Designing Meaningful Play within the Psycho-social Context of Older Adults. In Fun and Games '10.ACM, New York, USA, 84-93. 